\title{
RETRATO DE FAMILIA A CONTRALUZ: EL APRENDIZAJE MUSICAL DE ANGÉLIQUE DIDEROT Y LA EDUCACIÓN ILUSTRADA DE LAS MUJERES
}

\section{Family portrait against the light: Angélique Diderot's musical learning and women's education in the Enlightenment}

\author{
Miriam Bastos Marzal \\ Real Conservatorio Superior de Música de Madrid \\ Correo-e: bastosmarzal@yahoo.es
}

Recepción: 30 de noviembre de 20I8. Envío a informantes: I2 de diciembre de 2018 Aceptación definitiva: I de julio de 2019

RESUMEN: La esmerada educación musical proyectada por el filósofo francés Denis Diderot para su hija Angélique abarcó no solo el aprendizaje de un amplio repertorio para teclado, sino también nociones avanzadas de armonía y teoría musical. Partiendo de la conexión entre esta inusual opción pedagógica y las teorías de Diderot acerca de la deficiente educación recibida por las mujeres como causa de la supuesta inferioridad intelectual de estas, a través de este artículo pretendemos analizar la posible influencia de las ideas ilustradas en la vida musical de las mujeres en la Francia del último tercio del siglo xviı. Por otra parte, el análisis del repertorio para clave interpretado por Angélique, valioso testimonio de la vida musical desarrollada en el ámbito doméstico durante este período, nos permitirá acercarnos a un aspecto de la historia de la música, a menudo olvidado por el relato oficial, cuyas protagonistas fueron en su mayoría mujeres.

Palabras Clave: Diderot; educación; Ilustración; mujeres; música.

AвSTRACт: The musical education painstakingly planned by the French philosopher Denis Diderot for his daughter Angélique included not only a wide repertoire 
for the keyboard, but also advanced rudiments of harmony and musical theory. This inusual pedagogical choice, set against the theories of Diderot regarding the deficient education of women as being at the root of their supposed intellectual inferiority, is the starting point of this article. The aim is to analyse the possible influence of Enlightenment ideas on the musical life of women in France during the last third of the eighteenth century. In addition, our analysis to the repertoire for harpsichord interpreted by Angélique, valuable evidence of musical life in the domestic sphere in this period, will give us an insight into an aspect of the history of music often overlooked by the official account, whose protagonists were mostly women.

KeY words: Diderot; education; Enlightenment; women; music.

\section{Introducción}

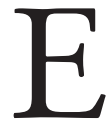
N LA Francia del siglo XVIII les philosophes son también melómanos fervientes. Voltaire escribe varios libretos de ópera; Rousseau no solo es teórico musical, sino también compositor, y D’Alembert, autor de varias obras musicales, participará con vehemencia en las querelles de su tiempo. Denis Diderot no es una excepción y tanto en sus novelas como en sus cartas, tratados, ensayos o artículos de la Encyclopédie queda constancia de su enorme interés por las más diversas cuestiones musicales: sus textos son a la vez testimonio de la vida musical de su época y eco de las polémicas estéticas que agitaron el siglo. El hechizo ejercido por la música sobre nuestro autor tendrá su reflejo en el modo como proyecta la educación de su propia hija.

Angélique Diderot (París, I753-I824), la única en alcanzar la edad adulta de los cuatro hijos nacidos del matrimonio formado por Denis y Marie-Antoinette, tenía nueve años cuando su padre decidió ocuparse de su educación. Se trataba de una cuestión que había sido motivo de agrias disputas entre la pareja ya que Diderot consideraba que el excesivo sentimiento religioso inculcado por la madre, católica ferviente, era perjudicial para la niña. Frente al empeño de Mme. Diderot, él siempre contempló con temor la posibilidad de que su hija estudiara interna en un colegio, como era costumbre entre las hijas de familias plebeyas de cierto nivel socioeconómico, ya que su propia hermana murió enclaustrada en un convento a los 28 años de edad tras padecer un grave trastorno mental. En i762, aprovechando una larga enfermedad de su esposa, decide finalmente que su hija se eduque en casa, siendo él mismo quien se ocupe de ello con gran entusiasmo ${ }^{2}$.

Chantal Grell dedica un capítulo a Angélique Diderot en una excelente monografía sobre la educación de las jóvenes nobles de la Europa de los s. XVII y XVIII³,

Ferrer, A.: Estética, política y música en tiempos de la 'Encyclopédie', Valencia, Universitat de València, 20I3.

Wilson, A.: Diderot, New York, Oxford University Press, 1972, pp. 594-96.

Grell, Ch.: L'éducation des jeunes filles nobles en Europe: XVII et XVIII siècles, Paris, Presses Universite Paris-Sorbonne, 2004. 
RETRATO DE FAMILIA A CONTRALUZ: EL APRENDIZAJE MUSICAL DE ANGÉLIQUE DIDEROT Y LA EDUCACIÓN ILUSTRADA DE LAS MUJERES MIRIAM BASTOS MARZAL

mientras que otros aspectos de la vida de esta joven, como el estrecho vínculo que la unió a su padre, han sido estudiados por Jeanette Geffriand Rosso ${ }^{4}$. Dicha relación ya había sido analizada anteriormente por Meghan K. Roberts, si bien esta autora la situó en el más amplio contexto de los lazos familiares que rodearon a varios pensadores de la épocas. Ambas aluden a la intensa dedicación de Diderot a su hija durante los años de aprendizaje de esta, así como al talento y la sensibilidad que demostró desde pequeña, pero no van más allá de una mera descripción de la relación entre los dos, sin referirse en ningún momento a la educación musical de la niña. Otros trabajos como los de Maciej Foryck y Monique Ruffet sí se han centrado en el especial interés de Diderot por proporcionar a su hija sólidos conocimientos tanto de física como de anatomía ${ }^{6}$. A partir de la publicación de sus obras completas por J. Assézat y M. Tourneux entre 1785 y I877, surgieron diversos estudios -ya algo anticuados- que abordaron las revolucionarias ideas pedagógicas del filósofo, como el de Avedik Mesrobian, quien dedica todo un capítulo a la educación de Angélique, relacionando las concepciones pedagógicas del pensador con sus reflexiones sobre psicología y moral7.

Sin embargo, en la correspondencia de Diderot y en otras obras suyas de ficción o de teoría musical se manifiesta un singular aspecto relacionado con la formación musical de Mlle Diderot que no aparece mencionado en ningún estudio, como son los extensos conocimientos de armonía y teoría musical que adquirió gracias a las clases recibidas de Anton Bemetzrieder (Dauendorf I739-Londres I808), profesor de origen alsaciano contratado por su padre cuando ella tenía dieciséis años ${ }^{8}$. Si bien es cierto que en los estudios anteriormente citados aparecen continuas referencias al excelente nivel que la joven demostraba como intérprete de clavecín, ninguno de ellos se detiene a analizar la circunstancia, totalmente insólita en su época, de que hubiese alcanzado un nivel tal de conocimiento teórico y práctico de armonía como para que Charles Burney, en su tratado Present state of Music in France and Italy, la alabara como «[...] una de la mejores clavecinistas de París, y que posee, para ser una mujer, un dominio extraordinario de la modulación»?

4 Geffriaud Rosso, J.: «Diderot et Angélique à travers la Correspondance: humain, trop humain», Revue belge de philologie et d'bistoire, vol. 70 n. ${ }^{\circ}$ 3 (1992), pp. 683-693.

Roberts, M. K.: Sentimental Savants: Philosophical Families in Enlightenment, Chicago, University of Chicago Press, 2016.

6 Foryck, M.: «A new education of Women. Denis Diderot's anatomy course project for young noble women», Biuletyn Historii Wychowania, n. ${ }^{\circ} 29$ (2013), pp. 7-I4 y RufFET, M.: «La physique pour débutants: Angélique Diderot et les Leçons de l'abbé Nollet», Recherches sur Diderot et sur l'Encyclopédie, vol. i3 n. ${ }^{\circ}$ I (1992), pp. 56-78.

Mesrobian, A.: Les conceptions pedagogiques de Diderot, New York, Burt Franklin, 1972.

8 GRIBEnski, J.: «Bemetzrieder, Anton», en $M G G$ Online, hrsg. von Laurenz Lütteken, Kassel, Stuttgart, New York, 20I6, última consulta: noviembre 2018.

9 Burney, Ch.: The Present State of Music in France and Italy, London, T. Becket \& Co. Strand, 1773. «Mademoiselle Diderot, his daughter, is one of the finest harpsichord-player in Paris, and, for a lady, possessed of an uncommon portion of knowledge in modulation». Todas las traducciones, tanto del francés como del inglés, son de la autora. Se ha mantenido en todos los textos la ortografía original de la correspondiente edición francesa. 
La formación musical recibida por Angélique no se limitó, pues, al aprendizaje de un modesto repertorio vocal o para clave, actividad que, junto a la pintura, la poesía o la costura, formaba parte de aquellos inocentes entretenimientos aconsejados para las jóvenes y cuyo disfrute se reducía al más estricto ámbito doméstico. En su caso, los sólidos conocimientos de armonía adquiridos pusieron de relieve tanto su talento como su carácter obstinado, y le proporcionaron los conocimientos teóricos necesarios para desarrollar una forma de creación musical como era la improvisación, yendo más allá de la mera función de intérprete.

Es preciso por otra parte tener en cuenta que la identificación de Diderot con las corrientes más radicales de la Ilustración le llevó a elaborar sus teorías sobre la sociedad partiendo de un principio de igualdad absoluta entre todos los seres humanos, dando lugar así a un análisis de la condición de las mujeres completamente diferente al de otros pensadores ilustrados como Montesquieu o Rousseau. Frente a afirmaciones como la vertida por este último en Les Confessions: «Todo París se dividió en dos partidos [...]. Uno, más fuerte y numeroso, compuesto por los grandes, los ricos y las mujeres, defendía la música francesa; el otro, más vivo, orgulloso y entusiasta, estaba formado por verdaderos expertos, gentes de talento y por los verdaderos genios $[\ldots]{ }^{10}$, Diderot en ningún momento cuestiona la capacidad de las mujeres, sino que atribuye la situación de inferioridad intelectual padecida por la mayoría a la mala e insuficiente educación que reciben: «[...] más reprimidas y más descuidadas en su educación, abandonadas al capricho de la suerte, con un alma más voluble, órganos más delicados y sin la firmeza, natural o adquirida que a nosotros nos prepara para la vida» ${ }^{\text {II }}$.

El caso de Angélique nos ofrece, pues, un campo de estudio por explorar a partir del cual podremos analizar el grado de influencia de las ideas ilustradas en la vida musical de las mujeres en la Francia del último tercio del xviıI. Y también comprobar hasta qué punto la personal opción pedagógica de este pensador inscrito en las corrientes más radicales de la Ilustración como fue Diderot pudo ser un modo de poner en práctica a través de determinadas decisiones tomadas en el ámbito familiar todas sus ideas acerca de la educación como medio de evitar la desfavorecida situación de las mujeres que él con tanta insistencia denunciara.

Las referencias de Diderot al repertorio para teclado interpretado por su hija Angélique nos permiten además acercarnos a una faceta de la vida musical en el París de los años 1760-I770 por la que la historia oficial suele pasar de largo: más allá de querelles y otras disquisiciones estéticas, los espacios privados

1o Rousseau, J. J.: Oenvres complètes avec des notes historiques I. «Les confessions. Discours. Politique», Paris, Chez Furne, I835, p. 200: «Tout Paris se divisa en deux partis plus [...] L'un, plus puissant, plus nombreux, composé des grands, des riches et des femmes, soutenoit la musique Françoise; l'autre, plus vif, plus fier, plus enthousiaste, étoit composé des vrais connoisseurs, des gens à talens, des hommes de génie».

II Diderot, D.: Essai sur les femmes. Oenvres Complètes, ed. de J. Assézat et M. Tourneaux, vol. II, p. 259. En lo sucesivo emplearemos la abreviatura O.C. para referirnos a dicha edición, seguida del número de volumen y la página correspondiente. «Plus constraintes et plus négligées dans leur éducation, abbandonnées aux mêmes caprices du sort avec un âme plus mobile, des organes plus délicats et rien de cet fermeté naturelle ou acquise qui nous prépare». 
fueron testigo de una intensa actividad musical llevada a cabo principalmente por mujeres.

La metodología empleada ha sido el vaciado de textos dispersos del filósofo y de estudios sobre su figura. Para las obras originales de Diderot se han elegido, como edición de referencia, las obras completas en 20 volúmenes publicadas en París entre I875 y 1877 por Garnier, a cargo de J. Assézat y M. Tourneaux, a excepción de las Leçons de clavecin et principes d'Harmonie, par M. Bemetzrieder, para la que se ha empleado la edición original de i77r. Podemos deducir el tipo de formación musical proyectada por el filósofo para su hija gracias a esclarecedoras referencias que aparecen en las dos obras que de modo más extenso tratan sobre música: Le neveu de Rameau y, sobre todo, Leçons de clavecin et principes d'Harmonie, par M. Bemetzrieder -en adelante, Leçons de clavecin-. En la abundante correspondencia que mantuvo con su hermana Denise; con Sophie Volland, su amante; o con sus amigos Melchior Grimm, Étienne Falconet y Charles Burney, o incluso con Carl $\mathrm{Ph}$. E. Bach, se pueden encontrar trazados algunos aspectos autobiográficos, mientras que en su ensayo Sur les femmes Diderot nos ofrece un lúcido análisis de la naturaleza de las mujeres y su situación en la sociedad. Finalmente, los diarios, las cartas y la crónica The present state of music in France and Italy del historiador inglés Charles Burney contienen asimismo valiosas alusiones a Mlle. Diderot. Todos estos textos se han interpretado a la luz de los conocimientos actuales sobre la práctica musical de las mujeres en diversos países centroeuropeos de aquel momento.

\section{La peculiar educación de Angélique}

Formar seres inteligentes y rectos, de mente abierta y que ocupen el lugar que les corresponde en la sociedad fue una de las principales preocupaciones de nuestro filósofo, y será precisamente el desarrollo intelectual y artístico de su única hija el mayor deleite del Diderot maduro. En su correspondencia aparecen continuas referencias al intenso placer que a él, como padre, le producía oírle tocar:

Mi hija es una niña encantadora que disfruta con todas las cosas buenas. Es casi una virtuosa de la música, pero te digo que no es esto lo que más valoro en ella ${ }^{12}$.

Estoy encantado con mi pequeña, ya que razona todo cuanto hace:-Angélique, ¿os habéis quedado atascada en ese pasaje? Mira la partitura. -La digitación no está escrita, por eso no puedo continuar. -Angélique, creo que os habéis saltado un compás. - ¿ Cómo me lo voy a saltar si todavía tengo el acorde en los dedos? $?^{13}$.

12 Diderot, D.: Lettre à Etienne Falconet (26 mayo 1769), O.C. XIX, p. 307. «Ma fille est un enfant charmante qui aime toutes les bones choses. C'est presque une virtuose en Musique et je te réponds que ce n'est pas ce que j'en estime le plus».

ז3 Diderot, D.: Lettre A Sophie Volland (3r julio 1762), O. C. XVIII, p. 87. «Je suis charmé de ma petite, parce qu'elle raisonne tout ce qu'elle fait. -Angélique, ce passage vous embarrasse ? regardez sur votre papier. -Le doigté n'est pas écrit sur mon papier, et c'est là ce qui m’arrête. -Angélique, je crois que vous passez une mesure. -Comment la passerais-je puisque j'en tiens encore l'accord sous mes doigts ?». 
Mientras que Le neveu de Rameau y las Leçons de clavecin podrían considerarse una especie de declaración de intenciones sobre la posible educación ideal que deseaba para su hija, a partir de la correspondencia de Diderot podemos esbozar su progreso, en ocasiones casi día a día, tal como fue narrada por él mismo. Hay que señalar que no siempre eran coincidentes, como vemos, por ejemplo, al contrastar un comentario de Le neven de Ramean, donde, a pesar de que el filósofo sostiene que la enseñanza del clavecín no le parece útil para su hija, ya que «nunca he tenido interés en un tipo de estudio que ocupa tanto tiempo y que sirve para tan poco» ${ }^{14}$, con la correspondencia de Diderot con Sophie Volland, sabemos que la niña tocaba el clavecín con su padre desde, al menos, los nueve años, como lo demuestra esta carta de 1762 : «Si me quedo en casa, hago repetir a la niña sus lecciones de clavecín. ¡Qué buenos dedos va a tener!,y con qué facilidad, flexibilidad y gracia lo hace! ${ }^{15}$.

Y sabemos por otra carta, fechada en septiembre de 1762 , que la historia también formaba parte de las materias que la niña estudiaba con su padre: "Con todos los amigos fuera de París, mis días son bastante monótonos. El plan es levantarse tarde, porque estoy perezoso, hacer repetir a la niña un capítulo de historia y una lección de clavecín» ${ }^{16}$.

Este dato, en cambio, sí parece coincidir con la respuesta dada por L'Elève en las Leçons de clavecin, cuando el maestro intenta averiguar qué otras materias estudia además de la música: ella afirma haber leído historia antigua, algunas historias particulares, incluso la Historie Universelle de Voltaire varias veces, pero reconoce que «[...] las batallas me aburren» $\mathrm{y} \ll[\ldots]$ todos esos nombres de villas, de montañas y de ríos son una pesadez» ${ }^{17}$.

Además de la música y la historia, Diderot supervisaba las lecturas de su hija, y también se ocupó de que aprendiera aritmética, contratando a Nollet -popular científico que había hecho dar saltos a monjes y a soldados aplicándoles descargas eléctricas- para que le diera clases particulares de física ${ }^{18}$. Cuando la niña se acercó a la pubertad, su padre requirió la asistencia de Marie-Catherine Bihéron, una comadrona que, con ayuda de unas reproducciones anatómicas en cera diseñadas por ella misma, enseñaba los secretos y mecanismos de la reproducción humana.

${ }_{14}$ Diderot, D.: Le neveu de Rameau, o. C. V, p. 4I3. «Mais peut-être ne me soucie-je pas trop de faire entrer dans le plan de son éducation une étude que occupe si longtemps et qui sert si peu». Se refiere precisamente al estudio del clavecín.

${ }_{15}$ Diderot, D.: Lettre à Sophie Volland (28 julio 1762), O.C. XVIII, p. 279. «Si je reste à la maison, je fais répéter à l'enfant ses leçons de clavecin. Les jolis doigts qu'elle aura! de l'aisance mollesse, de la grâce».

${ }_{16}$ Diderot, D.: Lettre à Sophie Volland (26 septiembre i762), O.C. XVIII, p. 338. «Dans l'absence de tous mes amis dispersés autour de Paris, mes journées sont assez uniformes. Se lever tard, parce qu'on est paresseux ; faire répéter à sa petite fille un chapitre d'histoire et une leçon de clavecin».

${ }_{17}$ Diderot, D.: Leçons de clavecin..., p. 135. A esto el Maestro señalará cómo las batallas y los nombres de los lugares no son los verdaderos objetos de la Historia ni de la Geografía, sino los productos de la tierra y los mares, así como los hombres, sus costumbres, sus opiniones, o sus creencias (ibid., p. 136).

${ }_{18}$ Ruffet, M.: «La physique pour débutants: Angélique Diderot et les Leçons de l'abbé Nollet», Recherches sur Diderot et sur l'Encyclopédie, vol. I3, n. ${ }^{\circ}$ I (1992), pp. 56-78. 
RETRATO DE FAMILIA A CONTRALUZ: EL APRENDIZAJE MUSICAL DE ANGÉLIQUE DIDEROT Y LA EDUCACIÓN ILUSTRADA DE LAS MUJERES MIRIAM BASTOS MARZAL

En definitiva, el objetivo último de Diderot será enseñar a su hija «a razonar correctamente, algo muy poco frecuente entre los hombres, y todavía menos, entre las mujeres», y así afrontar con entereza aquellas penalidades de la vida que son fruto de la debilidad de su organismo y de la extrema sensibilidad que, según el filósofo, padecen todas las mujeres ${ }^{19}$.

\section{El repertorio de Angélique}

No disponemos de dato alguno acerca de la edad exacta de Angélique cuando comenzó a recibir clases de música ni de quién guió sus primeros pasos, pero sí sabemos que una de las principales tareas que su padre se impuso cuando comenzó a ocuparse de su formación fue precisamente la de supervisar su estudio al clavecín. Con respecto al repertorio que interpretaba, Charles Burney, en su Present State of Music, afirmó: «Aunque he tenido el placer de escucharla durante varias horas (a Mlle Diderot), no tocó ninguna composición de autores franceses o ingleses, pues todos eran italianos o alemanes; no es difícil, por tanto, hacerse una idea de cuáles eran los gustos musicales de M. Diderot $»^{20}$.

Esto parece coincidir con el repertorio de L'Elève en las Leçons de clavecin ${ }^{21}$, formado por obras de Honavre, Eckard, Schobert y Wagenseil. Varias páginas más adelante también citará a Abel, Alberti, Jean Back (Johann Christian Bach) y Müthel $^{22}$. Y sabemos que su interés por la música alemana es tal que llega escribir a Carl Ph. E. Bach para solicitarle piezas inéditas para su hija ${ }^{23}$.

Más allá de cuáles fueran realmente las obras que formaban parte del repertorio para teclado de Angélique Diderot, a través de estas listas de autores se abre un atractivo campo de estudio en la medida en que constituyen un testimonio directo del repertorio para teclado que se interpretaba en el ámbito doméstico en el París del último tercio del siglo xviII, pero, sobre todo, porque no existen muchos testimonios que reflejen de un modo tan explícito el proceso a través del cual un aficionado concreto pudo realizar la transición desde el clavecín hasta el nuevo fortepiano. En efecto: a través de estas listas de autores interpretados por L'Elève se podría trazar una especie de línea genealógica que abarcaría desde las últimas composiciones realizadas para clavecín, como las de J. Christian Bach o Müthel, hasta aquellas que ya anticipan -y algunas, como Schobert, consolidanuna nueva escritura para el fortepiano. Es muy interesante comprobar cómo los años de formación de Angélique coinciden en gran medida con el proceso de

19 Diderot, D.: Le neven de Ramean O.C. v, p. 4I3. «A raisonner juste, si je puis, chose si peu commune parmi les hommes, et plus rare encore parmi les femmes».

20 Burney, Ch.: Op. cit., p. 392. «But though I had the pleasure of hearing her for several hours, not a Angle, French composition was played by her the whole time, all was Italian and German; hence it will not be difficult to form a judgment of M. Diderot's taste in music».

${ }_{21}$ Diderot, D. (ed. y autor): Leçons de clavecin et principes d'Harmonie, par M. Bemetzrieder, París, Chez Bluet, I77I, p. II4.

22 Diderot, D.: Leçons de clavecin..., p. 132.

23 Diderot, D.: Lettre à Carl Philipp E. Bach (30 abril 1774) O.C. XX, p. 94. 
evolución que condujo desde un patrón de escritura todavía clavecinística hasta un idioma ya concebido para el nuevo instrumento col piano e forte. Y, casualmente, el final de ese proceso de aprendizaje, que a pesar de todos los esfuerzos de su padre terminará poco tiempo después de la boda, también coincidirá con la compra al constructor Zumpe de un fortepiano como regalo de bodas, que Diderot adquirirá en Londres a través de su amigo Charles Burney: «El instrumento que deseo, señor y muy honorable doctor, es el pequeño pianoforte de Zumpe, con las teclas sobreañadidas $»^{24}$.

Pero Diderot consideraba que el estudio del clave en una mujer era inútil, como ya vimos que manifestaba en Le neveu, si no iba acompañado de un estudio de la teoría musical en profundidad. La explicación la encontraremos en uno de los diálogos de las Leçons de clavecin: «Si vemos a tantas mujeres abandonar en el guardamuebles el instrumento en el que sus manos han estado tanto tiempo cuando eran jóvenes, es porque no habían avanzado lo suficiente, y creo que si lo abandonaron es porque no merecía la pena ser conservado» ${ }^{25}$.

Por eso, cuando se le ofrece la oportunidad de proporcionar a su hija un conocimiento de los principios teóricos de la armonía aplicados al arte de improvisar, no duda en contratar al profesor Bemetzrieder.

\section{Las Leçons de clavecin: una representación diferente de lo femenino a través de L'Elève}

En I77I aparecen en París, con un prefacio de Diderot, las Leçons de clavecin et principes d'Harmonie, par M. Bemetzrieder, obra teórica redactada con finalidad didáctica que trata sobre los principios de armonía aplicados al arte de improvisar y de acompañar al clavecín. Aunque en el título aparezca Bemetzreider como autor, y el mismo Diderot manifieste que él se ha limitado a realizar la corrección del «francés tudesco» con el que el maestro se expresa, sin que pueda atribuírsele nada «ni del fondo, ni de la forma ni del método», actualmente no existe ninguna duda acerca de que fue el mismo Diderot el responsable de la redacción final de este tratado, basándose, eso sí, en todo el contenido teórico que el profesor trabajó en las clases con la hija del filósofo ${ }^{26}$. Está articulado en forma de diálogo a tres voces entre

24 Diderot, D.: Lettre au Docteur Charles Burney (28 octubre I77I), citado en: Durand-Sendrail, Béatrice (ed.): Diderot, écrits sur la musique, Paris, Éditions J. C. Lattès, 1987, p. I68. «L'instrument que je veux, Monsieur et très honoré docteur, est un petit piano-forte de Zumpe, avec les touches surajoutées». Se trataba de un piano-forte carré: un instrumento ligero, cuyas octavas estaban formadas por 18 notas, a diferencia de las I2 acostumbradas en los teclados temperados. De ahí probablemente la expresión touches sourajoutées: teclas sobreañadidas. Esto quizás también pueda explicar la extraña tonalidad elegida (sol sostenido mayor) para el preludio incluido en el tratado Leçons de clavecin, que con toda probabilidad fue compuesto por Angélique.

${ }_{25}$ Diderot, D.: Leçons de clavecin..., p. I28. «Si l'on voit tant de femmes reléguer dans le gardemeuble, l'instrument sur lequel elles ont eu si longtems les mains étant filles c'est qu'elles n'étoient pas assiez avancées; $\&$ je pense que ce qu'elles ont abandonné, ne valoit pas la peine d'être conservé».

26 Sobre la autoría de las Leçons de clavecin: Gribenski, J.: «A propos des Leçons de clavecin (177I): Diderot et Bemetzrieder», Revue de Musicologie, t. 66, n. ${ }^{\circ} 2$ (1980), pp. 125-178. 
RETRATO DE FAMILIA A CONTRALUZ: EL APRENDIZAJE MUSICAL DE ANGÉLIQUE DIDEROT Y LA EDUCACIÓN ILUSTRADA DE LAS MUJERES MIRIAM BASTOS MARZAL

Le Maître, Le Philosophe y L'Elève (El Maestro, El Filósofo y La Alumna) a través del cual se van intercalando preguntas y respuestas acerca no solo de cuestiones de teoría musical, sino también de problemas de tipo filosófico o estéticos, a la vez que nos ofrece algunos relatos de pequeños acontecimientos de la vida cotidiana con el objeto, suponemos, de brindar al lector una lectura más amena.

A pesar de que el contenido autobiográfico es innegable, las afirmaciones vertidas en este tratado por Le Philosophe no nos permiten establecer cuál fue realmente el nivel de conocimientos ni la destreza adquiridos por Angélique. A lo largo de la obra el filósofo, actuando como narrador, se dedica a alabar una serie de cualidades en su hija que muy probablemente fueron idealizadas -o incluso inventadas- por un padre tan orgulloso como lo estaba él de su talento. En cualquier caso, se trata de una imagen que nos permite conocer de primera mano las expectativas que el filósofo puso en la educación de su hija: al margen de lo que realmente sucedió, saber cómo le hubiese gustado que ocurrieran las cosas también puede formar parte de nuestro relato.

En los comienzos de este proceso de aprendizaje, Diderot hace exclamar al maestro cuando la oye tocar por primera vez:

La pieza que la señorita acaba de ejecutar es hermosa y difícil. La posición de sus manos es muy buena, y dará lo mejor de sí misma. Su fisonomía vivaz trasluce capacidad de penetración. Yo no sé si podrá componer alguna vez, pero si compone, será una música enérgica, ya que veo que la prefiere a la música suave y delicada ${ }^{27}$.

Después de varias jornadas de estudio en las que la alumna practica unos ejercicios preliminares propuestos por el profesor, su le padre comenta:

No sé, señor, si estáis satisfecho con mi hija, pero desde las primeras lecciones que le habéis dado, se ha dedicado al estudio con una aplicación que yo nunca había visto en ella. Se levanta entre las cinco y las seis de la mañana, y antes de que yo me despierte, ya lleva más de dos horas de estudio: escalas y arpegios mañana, tarde y noche ${ }^{28}$.

Y para que no quede duda del tesón con que su hija se entrega a los estudios, le hace exclamar: «Todo lo que os puedo decir es que yo recibiré vuestras enseñanzas con el mayor deseo de aprovecharlas y que si mis progresos no responden a vuestros desvelos, no será por falta ni de aplicación ni de buena voluntad. Lo que quiero, lo quiero de verdad. Vamos, señor; ¿por dónde empezamos?»²9.

27 Ibíd., p. II9. «La pièce que Mademoiselle vient d'exécuter est belle et difficile elle a les mains très-bien placées; il ne tiendra qu'à elle d'exceller. Sa physionomie vive annonce de la pénetration, je ne sais si elle composera jamais, mais si elle compose, ce fera de la musique forte; car je vois que son goût la préfere a la musique fine et délicate».

28 Ibid. «Je ne sçais Monsseur si vous êtes satisfait de ma fille; mais depuis - que vous lui avez remis vos premieres Leçons c'est la plus belle diligence, l'application la plus suivie que je connoisse. Aujourd'hui levée entre cinq \& six, elle avoit deux bonnes heures d'étude avant mon réveil: Games et roulades le matin, Games et roulades l'après-dîner, games et roulades le soir».

${ }_{29}$ Ibid. «Tout ce que je puis vous dire, c'est que je recevrai vos leçons avec le plus grand desir d'en profiter et que si mes progrès ne répondent pas à vos soins ce ne sera ni faute d'application 
El retrato de L'Elève que aparece esbozado en las Leçons de clavecin debió corresponderse bastante con la Angélique real: Wilson cita varias cartas en su biografía de Diderot en las que este describe su enorme sorpresa cuando acometió la tarea de formarla ya que era «la testarudez personificada» $»^{30}$. Cuando el maestro se dispone a empezar ya con las primeras nociones de armonía, el padre manifiesta el deseo de que no se descuide la lectura de piezas: «No olvidemos la ejecución y la lectura de las piezas. Hay que atacar todos los frentes a la vez, y, sobre todo, hija mía, la medida, la precisión, el gusto, el aplomo. ¿Has oído bien? El aplomo» ${ }^{31}$.

Ella se queja de que tiene buena memoria para todo excepto para la música, a lo que el maestro le contesta: «Si no recordáis lo que han compuesto los demás, todo lo que compongáis vos, sea bueno o malo, será vuestro. Se acabó el problema» ${ }^{32}$.

El retrato que nos ofrece Diderot, pues, es el de una joven de dieciséis años cuyo tesón y capacidad de esfuerzo son reconocidos y alabados por su maestro, quien además vislumbra su talento para componer música de carácter enérgico, considera su asertividad como un rasgo positivo, valora su capacidad creativa por encima de la facilidad para memorizar un repertorio ajeno y le recomienda que interprete sus piezas «con aplomo, con mucho aplomo». Esa imagen que el filósofo nos está ofreciendo de su propia hija, sea o no real, esté más o menos idealizada, será en cualquier caso muy diferente de aquellas representaciones de lo femenino que en esta época dejaron reflejadas en sus cuadros y grabados artistas como Fragonard, Greuze o Van Loos, a quienes el mismo Diderot tantas páginas de elogios dedicó en sus Salons. Y es también muy diferente de esa grotesca imagen de la desquiciada alumna de clave descrita en Le neveau de Rameau en una de las escenas más delirantes del libro:

ÉL: Llegaba. Me sentaba en una silla: ¡qué tiempo tan horroroso, hay que ver cómo están las calles! Chismorreaba algunas novedades [...]. Vamos, Mademoiselle, tomad vuestro libro. Mientras, Mademoiselle, sin apresurarse, busca el libro (lo ha perdido: que llamen a la doncella; la riñen), yo continúo (más chismes). [...]. Mientras tanto habían encontrado el libro bajo un sillón donde había ido a parar después de que un dogo o un gato lo hubiera arrastrado, masticado y desgarrado. Se ponía al clavecín. Al principio dejaba que hiciera ruido ella sola. Luego, tras un signo de aprobación hacia la madre, me aproximaba. La madre: «no lo hace mal, si pusiera más voluntad... pero no quiere, no quiere, prefiere perder el tiempo charlando, con sus trapitos, corriendo, o Dios sabe qué. Nada más salir vos de esta casa,

ni manque de bonne volonté. Ce que je veux je le veux bien. Voyons, Monsieur; par où commencerons nous?».

30 Wilson, A.: Diderot, New York, Oxford University Press, 1972, p. 455, n. 38.

${ }^{31}$ Diderot, D.: Leçons de clavecin..., p. I22. «Mais ne négligeons pas l'éxecution et la lecture des pieces; faisons marcher toutes les parties de l'art de front; et puis, mon enfant, de la mesure, de la précision, du goût; l'aplomb, entens tu, l'aplomb».

32 Ibíd., p. I52. «Hé bien, ne retenant rien des autres, si jamais vous composez, bon ou mauvais, ce que vous produissez sera vôtre». 
RETRATO DE FAMILIA A CONTRALUZ: EL APRENDIZAJE MUSICAL DE ANGÉLIQUE DIDEROT Y LA EDUCACIÓN ILUSTRADA DE LAS MUJERES MIRIAM BASTOS MARZAL

cierra el libro, para no abrirlo hasta vuestro regreso». Viéndome obligado a decir algo, le tomaba las manos y se las colocaba en otra posición. Me impacientaba. Gritaba: «¡sol, sol, es sol, Mademoiselle!». La madre: «¿no tenéis oídos? Yo, sin estar al clavecín y sin mirar el libro, noto perfectamente que falta un sol» [...] no retenéis nada de lo que dice, no avanzáis ni un milímetro [...]. Pasaba la hora. Mi discípula me hacía entrega del sobrecito con un gracioso gesto del brazo y una reverencia aprendida del maestro de baile y yo me lo metía en el bolsillo [...] eso es lo que entonces se llamaba una lección de acompañamiento ${ }^{33}$.

\section{Música para dilettanti}

Ante un planteamiento educativo tan original, tan meticulosamente trazado, donde al parecer nada ha sido dejado al azar, cabría pensar que Diderot, el pensador radical que tantas veces ha denunciado la injusta situación que viven las mujeres manifestando su profunda compasión por la mala educación que reciben, ha reconocido en su hija su condición de sujeto, y le está ofreciendo a través de esta esmerada educación una herramienta que le permita situarse intelectualmente en el mismo nivel que cualquier hombre, o incluso desempeñar una actividad de modo profesional. Pero en los diálogos de su tratado de armonía en ningún momento contempla esa posibilidad y, en cambio, hace exclamar a la alumna: «Leo sobre moral para aprender a comportarme, poesía para entretenerme, y hago música porque a mi padre le gusta» ${ }^{34}$. "Quiero estudiar armonía para tener el día de mañana una distracción inocente y agradable para mí y para los demás»35.

Y cuando ofrece a su padre como regalo de cumpleaños un preludio compuesto por ella misma, le dice con lágrimas en los ojos: «[...] faltaba mi preludio... lo he hecho lo mejor que he podido... deseo tanto que os guste, que me salga bien $[\ldots] »^{36}$.

33 Diderot, D.: Le neveu de Rameau, o.c. V, p. 4I8. "LUI: J'arrivais, je me jetais dans ma chaise. Que le temps est mauvais ! Je bavardais quelques nouvelles : [...] Allons, mademoiselle, prenez votre livre. Tandis que mademoiselle, qui ne se presse pas, cherche son livre qu'elle a égaré, qu'on appelle une femme de chambre, qu'on gronde, je continue [...] Cependant le livre de mademoiselle s'était retrouvé sous un fauteuil où il avait été traîné, mâchonné, déchiré par un jeune doguin, ou par un petit chat. Elle se mettait à son clavecin : d'abord elle faisait du bruit toute seule, ensuite je m'approchais, après voir fait à la mère un signe d'approbation. La mère : "Cela ne va pas mal ; on n'aurait qu'à vouloir, ais on ne veut pas ; on aime mieux perdre son temps chiffonner, à courir, à je ne sais quoi. Vous n'êtes pas sitôt arti, que le livre est fermé pour ne le rouvrir qu'à votre retour " [...] Cependant, comme il fallait faire quelque chose, je lui prenais les mains que je lui plaçais autrement ; je me dépitais, je riais, sol, sol, sol, mademoiselle, c'est un sol. La mère : "Mademoiselle, est-ce que vous n'avez point oreille ? Moi qui ne suis pas au clavecin, et qui ne vois pas ur votre livre, je sens qu'il faut un sol ". [...] L'heure se passait, mon écolière me présentait mon petit cachet avec la grace du bras et la reverence qu'elle avait apprise du maitre à danser; je le mettais dans ma poche, [...], et voilà ce qu'on appelait alors une leçon d'accompagnement ».

34 Diderot, D.: Leçons de clavecin..., p. 134. «Je lis de la Morale pour me conduire, de la poesie pour m'amuser, et je fais de la musique pour le plaisir de mon papa».

${ }_{35}$ Ibíd., p. I69. «Je veux faire d l'harmonie qui me prépare un jour a moi-même et aux autres un amusement aussi innocent qu'agréable».

${ }^{36}$ Ibíd., p. 302. «Excepté mon Prélude... J’ai fait de mon mieux. Je voudrois qu’il vous plût; je voudrois qu'il fût». 
Es evidente que la instrucción de la hija en los fundamentos de la armonía no pretende hacer de ella nada más que una aficionada de calidad, y que, en la imaginación del filósofo, el único motivo por el que Angélique debe seguir estudiando es dar gusto a su padre. Visto desde una perspectiva actual, es muy difícil entender y nos parece casi absurda la inutilidad de un esfuerzo económico en alguien como Diderot, que no era rico -justo en aquel momento se encontraba negociando la venta de su biblioteca a Catalina de Rusia para obtener unos ingresos con los que pagar la dote de la hija-, cuando el único objeto era proporcionarle a ella o proporcionarse a sí mismo una refinada distracción.

Este, para nosotros, inexplicable aspecto de la educación de Angélique solo adquiere sentido si lo situamos en el contexto más amplio de la actividad musical de las mujeres de la época. Si exceptuamos aquellas hijas o esposas de músicos que pudieron recibir una sólida formación musical en su entorno familiar y que desarrollaron una actividad de tipo profesional formando parte del servicio en las grandes cortes europeas -como fue el caso de Elisabeth Jacquet de la Guerre, en Versalles, o de Juliane Reichardt, en la corte de Federico el Grande de Prusia-, los espacios privados eran los únicos lugares donde una mujer podía exhibir sus dotes musicales sin caer en el desdoro o perder su estatus social. Tales espacios eran los salones de la alta burguesía y la aristocracia que encontramos constantemente descritos en la correspondencia de Diderot, como la carta dirigida a Sophie Volland de is de septiembre de 1760 desde La Chevrètte, la finca de recreo de Mme Epinay. En ella, el escritor nos ofrece un delicioso relato de una velada musical:

Estábamos en aquel triste y magnífico salón, donde formábamos, cada cual con su ocupación, un cuadro muy agradable: hacia la ventana que daba al jardín, M. Grimm se hacía retratar y Mme d'Epinay estaba apoyada en el respaldo de la persona que dibujaba [...]. M. de Saint Lambert leía en un rincón. Yo jugaba al ajedrez con Mme d'Houdetot. Mme d'Esclavelles charlaba con sus hijos, sentados en torno a ella. Dos hermanas de la persona que dibujaba a mi amigo bordaban, y una tercera tocaba al clave una pieza de Scarlatti.

Después de la cena hubo un poco de música. La persona de la que ya te he dicho que tocaba el clave tan suavemente, nos sorprendió gratamente a todos cantando, a unos por lo especial de su talento, y a mí por el encanto de su juventud de su dulzura y su modestia, por su gracia y su inocencia [...]. Los aplausos que le dedicaron le hicieron ruborizarse y le produjeron un encantador embarazo ${ }^{37}$.

37 Diderot, D.: Lettres à Sophie Volland (is septiembre 1760), O.C. XVIII, pp. 452-458. «Nous étions alors dans le triste et magnifique salon et nous, y formions, diversement occupés, un tableau très agréable. Vers la fenêtre qui donne sur les jardins, M. Grimm se faisait peindre et madame d'Epinay était appuyée sur le dos de la chaise de la personne qui le peignait. Un dessinateur assis plus bas, sur un placet, faisait son profil au crayon. Il est charmant ce profil ; il n'y a point de femme qui fût plus tentée de voir s'il ressemble. M. de Saint-Lambert lisait dans un coin la dernière brochure que je vous ai envoyée. Je jouais aux échecs avec madame d'Houdetot. La vieille et bonne madame D'Esclavelles, mère de madame d'Épinay, avait autour d'elle tous ses enfants, et causait avec eux et avec leur gouverneur. Deux sœurs de la personne qui peignait mon ami, brodaient, et une troisième essayait au clavecin une pièce de Scarlatti. Après dîner on fit un peu de musique. La personne dont je vous ai déjà parlé qui touchait si légèrement et si savamment du clavecin nous étonna 
RETRATO DE FAMILIA A CONTRALUZ: EL APRENDIZAJE MUSICAL DE ANGÉLIQUE DIDEROT Y LA EDUCACIÓN ILUSTRADA DE LAS MUJERES MIRIAM BASTOS MARZAL

Charles Burney se refiere al elevado estatus que se le suponía a quien se dedicara a la música como dilettante en el prólogo a su Present State of Music in France and Italy, donde incluye una especie de glosario con palabras en otras lenguas con su traducción al inglés, siendo esta la versión que ofrece del término dilettante: "Caballero compositor o intérprete, sinónimo del término francés amateur» $3^{8}$.

El caso de Angélique Diderot es similar al de Marianna Martines, compositora y cantante austriaca de origen español que vivió en la Viena de la segunda mitad del XVIII, a quien Giambattista Mancini describe del siguiente modo: «Si bien dilettante, puede llamarse con toda justicia gran maestra y singular genio de la música» ${ }^{39}$.

Del mismo modo, podemos citar el título que aparece en un volumen de 1767 en el que la autora reunió una colección de 22 arias y cuya única copia manuscrita se encuentra en el Conservatorio San Pietro a Majella de Nápoles: Scelta d'arie composte per suo diletto de Marianna Martines.

Una vez más, y esta vez en Viena, encontraremos al omnipresente Charles Burney alabándola sin reservas, impresionado por sus dotes de intérprete y de compositora: una mujer cuyo primer profesor fue el joven Joseph Haydn, que actuaba frecuentemente ante la emperatriz María Teresa y que recibió en su salón a los más importantes músicos de su tiempo. Una prolífica creadora que abordó una amplia variedad de géneros tanto vocal como instrumental y que escribió misas, oratorios, arias italianas, sonatas y conciertos. Ante tamaña capacidad creativa, surge de modo inevitable la pregunta de cómo es posible que pudiera ser considerada dilettante, resultando muy llamativa la aparente incompatibilidad entre el uso de este calificativo y el hecho de ser considerada a la vez grande maestra e raro genio della musica.

Esta supuesta contradicción no es tal si tenemos en cuenta que, en la época, un hombre que quisiera mantener un determinado estatus social no podía aceptar que las mujeres que dependían económicamente de él, es decir, su mujer, sus hijas o sus hermanas, realizaran ninguna tarea remunerada, porque la ociosidad de la mujer era signo de un nivel social elevado ${ }^{40}$. En una dama, pues, el diletantismo en cualquier ámbito de la actividad artística era símbolo de prestigio social y, con toda probabilidad, ni Marianna ni Angélique habrían tenido el menor interés en ser consideradas como profesionales de la música.

tous, eux par la rareté de son talent moi par le charme de sa jeunesse, de sa douceur, de sa modestie, de ses grâces et de son innocence. Les applaudissements qui s'élevèrent au- tour d'elle lui faisaient monter au visage une rougeur, et lui causaient un embarras charmant».

${ }_{38}$ Burney, C.: Op. cit., p. viii. «Dilettante: a gentleman composer or performer; synonymous with the French word amateur».

39 Mancini, G.: Riflessione pratiche sul canto figurato, Milano, Galeazzi, I777, citado en: GodT, I.: Marianna Martines: a woman composer in the Vienna of Mozart and Haydn, Rochester, University of Rochester Press, 20IO, p. I. «Sebbene dilettante, può a giusto titolo chiamarsi gran maestra, e raro genio della musica».

$4^{\circ}$ Loesser, A.: Men, Women and Pianos. A Social History, New York, Simon and Schuster, I954, p. 267. 


\section{Epílogo. La vida de casada de Mme de Vandeul}

Diderot insistirá en que su hija siga recibiendo la mejor de las instrucciones posibles después de su boda con el industrial Abel François Caroillon de Vandeul. Con la pretensión de que no deje de ejercitarse con la música, y a pesar de estar ya casada, el padre seguirá asumiendo los gastos de dos profesores: «Quiero que mi hija no pierda un talento que le ha costado tanto esfuerzo y a mí tanto dinero. Necesita dos maestros: uno para el acompañamiento y la armonía, y otro para las piezas. Yo pagaré los dos, y sólo pido una cosa: que lo aproveche» ${ }^{41}$.

Pero la vida de de Angélique acabó siendo muy diferente a lo que su padre había proyectado. Dos meses más tarde Diderot escribe a su amigo Melchior Grimm una amarga carta en la que describe la inutilidad de sus esfuerzos, anulados -según él- por la vanidad y el egoísmo de su yerno, que está convirtiendo a su esposa en un ser frívolo y pendiente únicamente de su aspecto físico: «Estoy pagando a Eckard una fortuna por sus clases. Al marido le importa un rábano, y la mujer, que no atiende más que a los gustos perversos de su marido, se preocupa de ello bien poco» ${ }^{42}$.

El pesimismo del padre está bien fundado: Angélique abandonará la música poco tiempo después de contraer matrimonio ${ }^{43}$. En una hermosa y triste carta escrita a su hija cuatro días antes de un enlace que había sido totalmente acordado y organizado entre los padres de los novios, el filósofo lamenta con amargura la salida de Angélique del hogar paterno y se siente en la obligación de detallarle sus nuevos deberes. Subraya la dependencia de la mujer, que pasa de la autoridad del padre a la del marido, y confirma la indisolubilidad del matrimonio y la exigencia de plegarse a los gustos del marido, de respetarle y de estimarle. Debe ser dulce, complaciente y alegre; debe atender -por interés del marido- a las cuestiones domésticas y, sobre todo, debe ser muy estricta con sus propias costumbres y cuidarse de la opinión pública, ya que la sociedad está en su derecho de juzgar a las mujeres a través de las apariencias, y ha de limitar al máximo sus relaciones, porque donde hay mucha gente, hay también mucho vicio ${ }^{44}$.

Es sorprendente el enorme conformismo que destila esta carta con una sociedad tan hipócrita y conservadora como era la suya: aquí podemos constatar del modo más claro el divorcio entre la obra pública del escritor y sus pensamientos más íntimos. Frente a unas delirantes creaciones de su imaginación (Les Bijoux indiscrètes, Jacques le fataliste) donde siempre aparecen jóvenes alegres y

${ }_{41}$ Diderot, D.: Lettre à sa soeur Denise (25 septiembre 1772), citado en: Gribenski, J. Op. cit. «Je veux que mon enfant ne laisse pas un talent qui lui a tant couté de peines, et a moi tant d'argent. Il lui faut deux.

${ }_{42}$ Diderot, D.: Lettre à Melchior Grimm (9 diciembre 1772) citado en: Gribenski, J. Op. cit. «Je paye à Eckard des leçons fort chères. Le mari s'en fout; et la femme, qui étudie du matin au soir tous les petits goûts pervers du mari, s'en soucie peut-être fort peu».

${ }_{43}$ No hay pruebas concluyentes sobre este punto. Nosotros citamos la argumentación de MAsSiest Du Biest, J.: La fille de Diderot. Mme de Vandenl, Tours, a cargo del autor, 1949, p. I6I.

${ }_{44}$ Diderot, D.: Lettre à Mme Caroillon, neé Diderot (13 septiembre 1772) citado en: GeFfriaud Rosso, J.: Op. cit. 
RETRATO DE FAMILIA A CONTRALUZ: EL APRENDIZAJE MUSICAL DE ANGÉLIQUE DIDEROT Y LA EDUCACIÓN ILUSTRADA DE LAS MUJERES MIRIAM BASTOS MARZAL

atolondradas en busca de placer, frente al paraíso de libertad que recreó en la isla de Haití en Le Suplément du voyage de la Bongainville, le vemos dispuesto a encerrar a su bien más preciado en una doble prisión: la de su nuevo hogar de recién casada donde va a quedar a disposición de un marido impuesto y la de una estricta regla moral con la opinión pública como encargada de vigilar su cumplimiento.

Cuando se trata de defender los supuestos intereses de Angélique, su actitud frente a la sociedad es sorprendente: ya no la ataca, sino que se vuelve cómplice de ella. No quiere bajo ningún concepto que su hija forme parte de ese otro grupo de mujeres independientes, inteligentes y creadoras como Mme de Geoffrin, Mme d'Epinay, Sophie Volland, Mme Riccoboni o Mlle La Chaux, con quienes mantuvo una estrecha relación de amistad e intercambio intelectual durante gran parte de su vida.

Diderot, pensador ilustrado radical que de joven prefirió vivir en la miseria antes que dedicarse a nada que pudiera suponer una limitación a su desarrollo intelectual, después de haberse rebelado contra la sociedad en nombre del libre albedrío hasta el punto de padecer la cárcel, de haber desafiado al poder establecido en sus escritos satíricos y, de modo oculto, pero no menos peligroso, en sus artículos de L'Encyclopédie, no nos ofrece en absoluto, a través de la educación de su hija Angélique, nada que pudiera considerarse un ejemplo de cómo llevar a cabo a través de la vida real aquello que tan fervientemente defendió en sus escritos.

Desde el punto de vista del Diderot padre, la educación que proyectó para su hija Angélique en realidad fue un experimento doblemente fallido, no solo porque su vida de casada acabó tomando un rumbo muy diferente al que hubiera querido para ella, sino también -y quizás precisamente por ello-, porque este desarrollo intelectual tan meditado y tan costoso que proyectó para su hija no tenía como objetivo su emancipación, sino únicamente proporcionarle un entretenimiento refinado y honesto que actuara como barrera ante otro tipo de distracciones que pudieran comprometer su imagen de respetable mujer casada: «Las distracciones de una vida ocupada y consciente doblegan nuestras pasiones. La mujer incuba las suyas: se trata de un punto fijo, sobre el que su ociosidad o la frivolidad de sus funciones mantiene su mirada incesantemente fija»45.

Desconocemos si el caso de Angélique fue único. Únicamente disponemos de indicios de un caso similar: Madame Gougelet, autora de un método de bajo cifrado y de al menos una recopilación de arreglos para teclado de arias de ópera, ambos de I77I, aunque se trata de un personaje de quien no existe referencia biográfica alguna ${ }^{46}$. En un momento en que están a punto de desaparecer la familia y los gremios como vías de transmisión de conocimiento accesibles al menos para

45 Diderot, D.: Essai sur les femmes, O.C. II, p. 257. « Je paye à Eckard des leçons fort chères. Le mari s'en fout; et la femme, qui étudie du matin au soir tous les petits goûts pervers du mari, s'en soucie peut-être fort peu ».

${ }^{46}$ Mme Gougelet: Recueil d'airs tirés des opéras-comiques, arrangés pour le clavecin ou le forte piano par Mme Gongelet, Oenvre II. Mis au jour par M. Hugard, I77I (Fuente: BNF) y «Méthode ou abrégé des règles d'accompagnement de clavecin», Paris, I77I, en Saint Arroman, J.: Basse continue: France 1600-I80o, Courlay, Fuzeau classique, 2006, vol. 5, pp. 356-4II. 
las mujeres pertenecientes a familias de músicos, y cuando aún faltan décadas para que a ellas les sea permitido acceder a la enseñanza reglada de los conservatorios para formarse como compositoras ${ }^{47}$, sería de enorme utilidad llevar a cabo un estudio más amplio acerca del aprendizaje de los fundamentos de la composición por medio de la enseñanza privada.

Quedémonos, pues, con esta imagen -tan utópica en muchos aspectos aún hoy como lo fue en tiempos de Angélique Diderot-de mujer creativa, inteligente, concienzuda, espontánea, impaciente por aprender y capaz de conseguir aquello que desea, que imaginó un hombre profundamente honesto consigo mismo y con sus semejantes, a excepción de su propia hija, a quien quizás solo supo querer como bien de su propiedad.

Y quedémonos también con ese otro París en el que sus habitantes aprendían, se entretenían o se enamoraban escuchando un repertorio del que no se ocupa casi nunca la historia de la música, tan pendiente siempre de los grandes eventos y de las querelles -esas «batallas» que tanto aburrían a la alumna-, olvidando que no solo se hacía música en Versalles o sobre los escenarios de los teatros de ópera, sino también en el interior de los hogares, entre amigos, y con el entretenimiento como único objetivo. Un repertorio en el que, a mi entender, nunca se profundiza lo suficiente como es el formado por la música de la vida cotidiana, y cuyas protagonistas desde siempre fueron las mujeres.

47 Ramos López, P.: Feminismo y música, Barcelona, Narcea Ediciones, 2003, p. 55. 